Bangladesh J. Bot. 44(3): 373-378, 2015 (September)

\title{
FUNGI ASSOCIATED WITH EGG MASSES AND FEMALES OF PLANT PARASITIC NEMATODE MELOIDOGYNE INCOGNITA (NEMATODA: HETERODERIDAE)
}

\author{
Mehmet KaRaKas* \\ Department of Biology, Faculty of Science, Ankara University 06100 Tandogan-Ankara, Turkey
}

Key words: Meloidogyne incognita, Root-knot nematode, Nematophagous fungi

\begin{abstract}
Egg masses and females of Meloidogyne incognita from a tomato (Lycopersicon esculentum Mill. cv. Falcon) field from Central Anatolia of Turkey, were collected and examined for the presence of fungi. Of the 138 egg masses of M. incognita 35.5\% were colonized by one or more of 9 species of genera Arthrobotrys, Cylindrocarpon, Fusarium, Paecilomyces, Plectosphaerella, Rhizoctonia and Verticillium while 31.8\% of the 138 females were colonized by 6 species, from the same genera except Paecilomyces and Plectosphaerella. Fusarium oxysporum was by far the predominant species in both the egg masses and females of M. incognita.
\end{abstract}

\section{Introduction}

Biological control of plant-parasitic nematodes using nematophagous or nematode-destroying fungi has received considerable attention recently, because of the urgent need for alternatives to replace synthetic nematicides that are being phased out due to environmental concerns (Kerry 1990). Nematophagous fungi are microfungi that can capture, kill and digest nematodes. They use special mycelial structures, the so-called traps, or spores to trap vermiform nematodes or hyphal tips to attack nematode eggs and cysts before penetration of the nematode cuticle, invasion and digestion (Nordbring-Hertz et al. 2006).

Meloidogyne incognita (Kofoid and White 1919) Chitwood, 1949 is a nematode, under the family Heteroderidae. Mature females are saccate (pear-shaped) but males are vermiform. It is an important plant parasite classified in Plant Pathology as in root-knot nematodes, as they prefer to attack the root of their host plant (Williams 1973).

When $M$. incognita attacks the roots of plants, it sets up a feeding location, where it deforms the normal root cells and establishes giant cells. The roots become gnarled or nodulated, forming galls, hence the term "root-knot nematode (RKN)". It is commonly called the "southern root-knot nematode" or the "cotton root-knot nematode". This parasitic roundworm has worldwide distribution and numerous hosts. These include most cultivated crops and ornamentals (Potter and Olthof 1993).

Since nematophagous fungi were first discovered in soil in 1852 (Fresenius 1852), more than 200 species of fungi have been identified as colonizers of cysts, females and eggs of plant parasitic nematodes. Less than 20 species of fungi were found colonizing eggs of Meloidogyne spp. (De Leij and Kerry 1991, Chen et al. 1996, Khan and Akram 2000). Relatively fewer species of fungi have been identified as colonizers of females of Meloidogyne spp. (Jatala 1986). The most common fungal genera included Cylindrocarpon, Fusarium, Gliocladium, Paecilomyces, Phoma and Verticillium (Clovis and Nolan 1983). The percentage of eggs of RKN colonized by fungi ranged from 29 to 50 (Morgan-Jones et al. 1984, Chen et al. 1996). Two possible routes for

*<mkarakas@science.ankara.edu.tr>. 
biological management of plant parasitic nematodes have been proposed. The first is massproduction an effective nematode-destroying fungus in the laboratory, and then apply it to soil (Coosemans 1991). The second is enhancing the natural nematophagous fungal populations in soil by altering their surrounding conditions. So far, commercial success of these approaches has been limited; however, there are encouraging reports on reducing nematode populations by adding certain kinds of amendments, such as chitin and green manure crops to soil (Schlang et al. 1988).

The objective of this study was to investigate the species and frequencies of fungi colonizing egg masses and females of RKN collected from Central Anatolia of Turkey.

\section{Materials and Methods}

Soil samples infested with Meloidogyne incognita were collected from a tomato field in the province Ayaş, Turkey $\left(40^{\circ} 0.18^{\prime} \mathrm{N} ; 32^{\circ} 19.2^{\prime} \mathrm{E}\right)$. Monthly root samples were collected from the tomato field previously identified as infested with Meloidogyne incognita. The samples were taken on zig zag pattern over the field. Roots were washed to free the soil with a fine jet of water. The females were picked off the roots and recorded whether infected (grey) or healthy (white). The egg numbers were determined per $1 \mathrm{~g}$ of roots by crashing the females. The healthy and diseased eggs were counted with the aid of a microscope (x 400) in three replicates for each sampling time.

The effect of parasites upon eggs in females was determined using the following two categories: (a) infested eggs - those developing a fungal colony and eggs that were not identifiable as juveniles or embryos, and (b) normal eggs - those containing embryos or second-stage juveniles.

Part of the soil collected from the field was used in a pot experiment. Surface sterilized seeds ( $0.1 \%$ mercuric chloride for $2 \mathrm{~min}$ ) of tomato were sown in sterilized soil. Twenty days after germination the seedlings were thinned to one per pot. Pots were filled with infested soil and planted with tomato seedlings (Lycopersicon esculentum Mill. cv. Falcon). The plants were inoculated with freshly hatched juveniles of $M$. incognita at a rate of $1000 /$ pot. Three pots were removed at monthly intervals and 10 females were randomly chosen from each pot, rinsed several times in sterile water, and preserved at room temperature in sterile sand in glass vials. The females were separated from sand, crushed in water, and the numbers of the disease and healthy eggs were recorded.

Part of the soil collected from the infested field was steam-sterilized and put into 24 pots. A second set of 24 pots were filled with infested field soil. Tomato plants were placed in the pots and inoculated with 1000 juveniles/pot in a water suspension pipetted around the roots. The pots were examined more frequently and when the females emerged they were examined at x 400 magnification to ascertain if there was any fungal infection. Weekly counts of healthy and diseased eggs were recorded in both of the sets in three replications.

Fungi were isolated from the eggs. The surface of the egg-masses was sterilized by agitation for $3 \mathrm{~min}$ in $5 \mathrm{ml}$ of $0.1 \% \mathrm{NaOCl}$, then removed and washed twice with sterile distilled water. They were carefully crushed in distilled water and the suspension was placed in Petri dishes containing oat agar (Kerry and Crump 1977). The plates were incubated at room temperature for 21 days to allow fungi to grow. Identification of the nematophagous fungi was based on the morphological characteristics of conidiophores and conidia (Barron 1977, Domsch et al. 1980, Gerlach and Nirenberg 1982, Nelson et al. 1983). If needed, nematodes were added to fungal cultures to induce sporulation for identification. Sporulation was also induced in some cultures by exposing fungal mycelium to a black light lamp (Model X-15B 115 volts $60 \mathrm{~Hz}$ ). 


\section{Results and Discussion}

Of the total of 138 egg masses and 138 females of $M$. incognita examined, $35.5 \%$ of the egg masses and $31.8 \%$ of the females were colonized with fungi (Table 1). Nine species of fungi were isolated and identified from egg masses, while only six species were isolated from females. Five of the six species were also isolated from egg masses. Cylindrocarpon destructans (Zinser) Scholten (Fig. 1b), Fusarium sponotrichioides Sherbakoff (Fig. 1f), Paecilomyces lilacinus (Thom) Samson (Fig. 1g) and Plectosphaerella cucumerina (Lindf.) W. Gams (Fig. 1h) were isolated only from egg masses. Rhizoctonia solani Kuhn (Fig. 1i) was the only fungal species to be associated only with females. Arthrobotrys oligospora Fresenius (Fig. 1a), Cylindrocarpon didymum (Harting) Wollenweber (Fig. 1c), Cylindrocarpon olidum (Wollenweber) Wollenweber (Fig. 1d), Fusarium oxysporum Schlechtendahl (Fig. 1e) and Verticillium chlamydosporium Goddard (Fig. 1j) were associated both egg masses and females of M. incognita. Fusarium oxysporum was isolated from $10.1 \%$ of the egg masses and from $8.6 \%$ of the females, whereas $V$. chlamydosporum was isolated from $3.6 \%$ of the egg masses and from $5.0 \%$ of the females of $M$. incognita. Two species of Cylindrocarpon were isolated from both egg masses and females.

Table 1. Fungal species associated with egg masses and females of Meloidogyne incognita from tomato fields of Central Anatolia in Turkey.

\begin{tabular}{lccccc}
\hline Fungal species & \multicolumn{2}{c}{ Egg masses } & & \multicolumn{2}{c}{ Females } \\
\cline { 2 - 3 } \cline { 5 - 6 } & Number & Percentage & & Number & Percentage \\
\hline Arthrobotrys oligospora & 6 & 4.3 & & 7 & 5.0 \\
Cylindrocarpon destructans & 2 & 1.4 & & - & - \\
C. didymum & 3 & 2.1 & & 3 & 2.1 \\
C. olidum & 3 & 2.1 & & 4 & 2.8 \\
Fusarium oxysporum & 14 & 10.1 & & 12 & 8.6 \\
F. sponotrichioides & 4 & 2.8 & & - & - \\
Paecilomyces lilacinus & 2 & 1.4 & & - & - \\
Plectosphaerella cucumerina & 10 & 7.2 & & - & - \\
Rhizoctonia solani & - & - & 11 & 7.9 \\
Verticillium chlamydosporium & 5 & 3.6 & & 7 & 5.0 \\
Total colonized by fungi & 49 & 35.5 & & 44 & 31.8 \\
\hline
\end{tabular}

The fungi most frequently isolated from egg masses were species of Fusarium and Cylindrocarpon. Fusarium oxysporum was isolated from $10.1 \%$ of the egg masses, Cylindrocarpon spp. from $5.6 \%$, and P. cucumerina from $7.2 \%$. Other species had relatively low frequencies of association with egg masses.

The fungi most frequently isolated from females were $F$. oxysporum $(8.6 \%)$ and $R$. solani $(7.9 \%)$. Females that were grey coloured often yielded fungi, whereas the white-cream coloured females did not.

The nematodes are a very important part in root decay complexes involving the nematodes, the plant, and the fungi or bacteria. The metabolic activities of any one part of the complex influence those of the other components. Root-knot nematode infections on certain hosts effectively predispose these roots to subsequent invasion by a range of other organisms present in the rhizosphere. Although some aspects of the biology of fungi infecting the eggs of root-knot 
nematodes are known, their mode of action is not yet fully understood (Fattan and Webster 1983). The composition of the associated mycoflora of individual fields probably is determined by such factors as plant host, cropping history, soil fertility, and climatic conditions. There is need to understand the effects of cropping sequences, cultural practices, and fungicides on the population of fungi associated with nematodes. The mycoflora associated with plant parasitic nematodes shows a wide capacity for adaptation to seasonal changes in temperature (Rodrigues-Kabana et al. 1984).
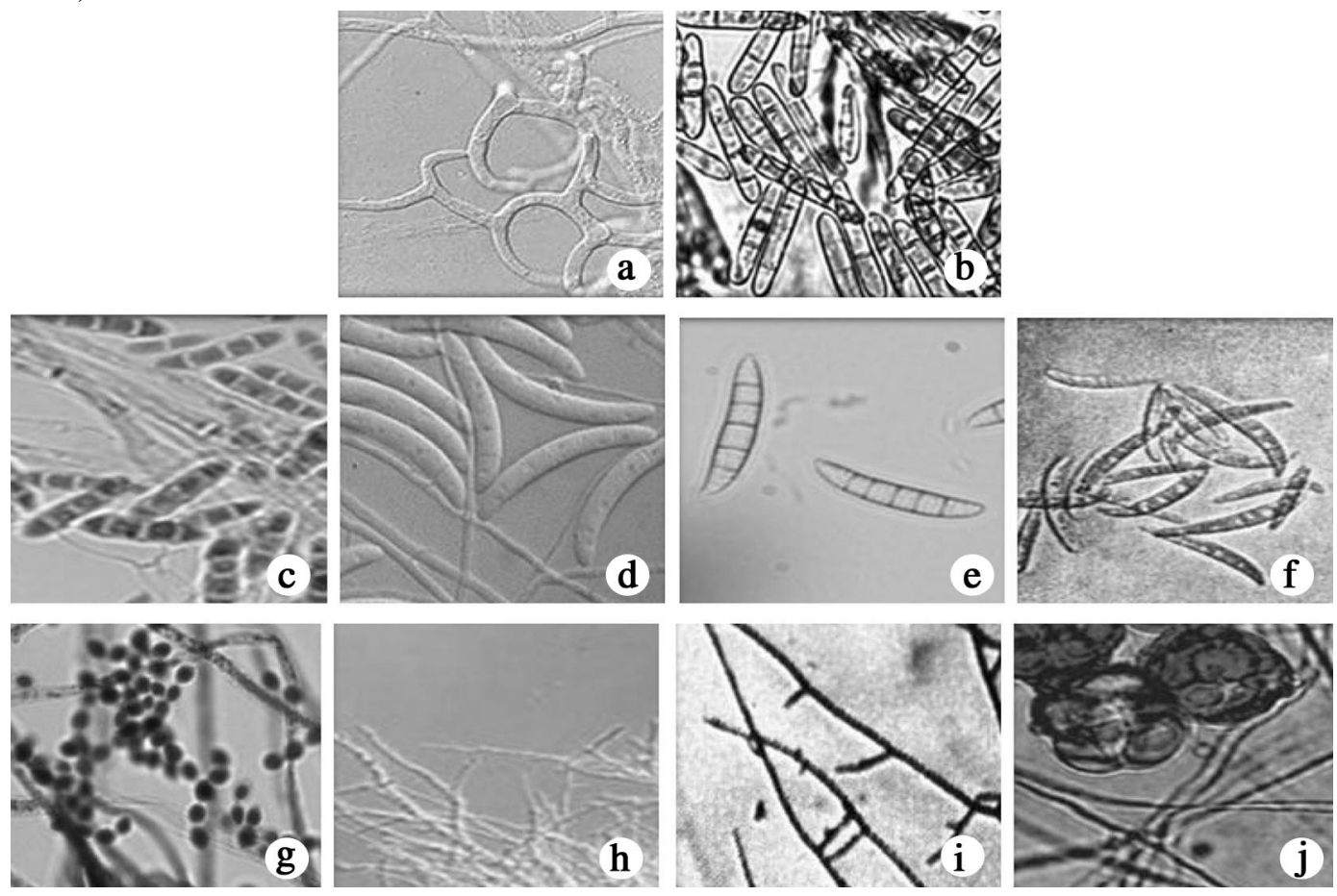

Fig. 1a-j. Fungi associated with egg masses and females of Meloidogyne incognita: (a) Arthrobotrys oligospora $(\times 400)$, (b) Cylindrocarpon destructans $(\times 1000)$, (c) Cylindrocarpon didymum $(\times 400)$, (d) Cylindrocarpon olidum $(\times 1000)$, (e) Fusarium oxysporum $(\times 400)$, (f) Fusarium sponotrichioides (× 400), (g) Paecilomyces lilacinus $(\times 1000),(\mathrm{h})$ Plectosphaerella cucumerina $(\times 100)$, (i) Rhizoctonia solani $(\times 100)$, (j) Verticillium chlamydosporium $(\times 400)$.

This survey showed that numerous fungi associated with egg masses and females of root-knot nematode, $M$. incognita. Fungi encountered in females are generally parasites, while many species of fungi isolated from egg masses are saprophytic because they can use the non-live substrate, gelatinous matrix, in the egg masses. Cylindrocarpon destructans has been reported as an egg parasite of several cyst nematodes (Dackman and Nordbring-Hertz 1985). Paecilomyces lilacinus is a well-known egg parasite of Meloidogyne spp. (Jatala 1986, Dube and Smart 1987). A Fusarium species associated with egg masses but not females has been reported to be an eggparasite (Morgan-Jones et al. 1983, 1984). Plectosphaerella cucumerina has been reported to be associated with cyst of Heterodera glycines (Carris et al. 1989), but whether it is an egg parasite or not needs further study. The fact that $R$. solani colonized only females, but neither egg masses nor cysts of cyst nematodes suggests that this fungus did not come from egg masses but from the host plant. Rhizoctonia solani is a well-known endotrophic mycorrhizal fungus (Harley 1968), 
which suggests that this fungus colonizes females of RKN through plant cells, rather than through egg masses. The study shows that females of RKN buried in the plant are still vulnerable to attack by soil fungi.

All the fungi isolated from M. incognita have been reported to be associated with plantparasitic nematodes, especially cyst-forming nematodes. But the mycofloras of the cyst nematodes may be different from the mycoflora of RKNs, which is probably due to the fact that the cyst is not a living stage of a nematode. It is not surprising that most fungi associated with females and egg masses as well, since females and egg masses are in close contact within the galls. More fungal species were identified as colonizers of egg masses than of females.

A few of them have been proven to be obligate parasites of nematodes but most of them are opportunistic parasites and saprophytes. For those obligate parasites, their effectiveness in destroying nematodes in vitro has not led them to be successful bio-control agents of plantparasitic nematodes. However, there are reports which indicate that viability of nematodes was greatly reduced after being colonized by some of these opportunistic fungal parasites in laboratory (Nigh et al. 1980). In soil, the populations of these opportunistic fungi associated with nematodes can be significantly greater than populations of obligate parasites (Yu 1989). The suppressiveness of suppressive soils against plant-parasitic nematodes has been reported to be positively related to the population of all the fungal parasites, including the opportunists (Kerry 1988). Although a great deal of knowledge is lacking on the mode of action and population dynamics of these opportunistic fungal parasites, their importance in future integrated management of plant-parasitic nematodes should not be underestimated. The association of a nematode-trapping fungus, $A$. oligospora, with egg masses and females of $M$. incognita is not surprising, because this fungus is saprophytic.

One important aspect of nematophagous fungi is the possibility of using them for biological control of plant- and animal- parasitic nematodes. Plant parasitic nematodes, e.g. root knot and cyst nematodes, are global pests in agriculture and horticulture, causing severe yield losses.

Owing to the ban of many nematicides, e.g. methyl bromide, because of health and environmental concerns, new alternatives for nematode control are, therefore, needed. Biological control may be such an alternative.

Mostly, plant parasitic nematodes attack plant roots and, therefore, the ability of the nematophagous fungi to grow in the rhizosphere is of great importance for their capacity to control these nematodes.

\section{References}

Barron GL 1977. The nematode-destroying fungi. Guelph, Ontario: Canadian Biological Publications 140 pp.

Carris LM, Glave DA, Symth CA and Edwards DI 1989. Fungi associated with populations of Heterodera glycines in two IIlinois soybean fields. Mycologia 81: 66-75.

Chen S, Dickson DW and Whitty EB 1996. Fungi associated with egg masses of Meloidogyne incognita and M. javanica in a Florida tobacco field. Nematropica 26: 153-157.

Clovis CJ and Nolan RA 1983. Fungi associated with cysts, eggs and juveniles of the golden nematode (Globodera rostochiensis) in Newfoundland. Nematologica 29: 345-356.

Coosemans J 1991. Methods for introducing Verticillium chlamydosporium into soil. IOBC/WPRS Bull. 14: $39-46$.

Dackman C and Nordbring-Hertz B 1985. Fungal parasities of the cereal cyst nematode Heterodera avenae in southern Sweden. J. Nematol. 17: 50-55.

De Leij FAAM and Kerry BR 1991. The nematophagous fungus Verticillium chlamydosporium as a potential biological control agent for Meloidogyne arenaria. Rev. Nematol. 14: 157-164. 
Domsch KH, Gams W and Anderson TA 1980. Compendium of soil fungi. Vol. 1 Academic Press, New York. pp. 859.

Dube B and Smart Jr GC 1987. Biological control of Meloidogyne incognita by Paecilomyces lilacinus and Pasteuria penetrans. J. Nematol. 19: 222-227.

Fattan F and Webster JM 1983. Ultrastructural changes caused by Fusarium oxysporum in Meloidogyne javanica. J. Nematol. 15: 35-41.

Fresenius G 1852. Beitrage zur mycology. Heft 1-2. pp. 1-80.

Gerlach W and Nirenberg H 1982. The genus Fusarium. A Pictorial Atlas. Biologische Bundesanstalt für Land-und Forstwirtschalt. Institut für Microbiologie, Berlin-Dahlem. pp. 406.

Harley JL 1968. Mycorrhiza. In GC Ainsworth and AS Sussman (eds), The Fungi, Vol. 3, The fungal population. Academic Press, New York. pp. 139-171.

Jatala P 1986. Biological control of plant-parasitic nematodes. Annu. Rev. Phytopathol. 24: 453-489.

Kerry BR and Crump OH 1977. Observation on fungal parasites of females and eggs of the cereal cyst nematode Heterodera avenae and other cyst nematodes. Nematologica 23: 193-201.

Kerry BR 1988. Fungal parasites of cyst nematodes. Agric. Ecosyst. Environ. 24: 293-305.

Kerry BR 1990. An assessment of progress toward microbial control of plant-parasitic nematodes. Suppl. J. Nematol. 22: 621-631.

Khan MR and Akram M 2000. Effect of certain antagonistic fungi and rhizobacteria on wilt complex caused by Meloidogyne incognita and Fusarium oxysporum on tomato. Nematol. Medit. 28: 139-144.

Morgan-Jones G, White JF and Rodrigues-Kabana R 1983. Phytonematode pathology. Parasitism of Meloidogyne arenaria eggs by Verticillium chlamydosporum. Nematropica 13: 245-260.

Morgan-Jones G, White JF and Rodrigues-Kabana R 1984. Fungal parasites of Meloidogyne incognita in an Alabama soybean field soil. Nematropica 14: 93-96.

Nelson PE, Toussoun TA and Marasas WFO 1983. Fusarium species. An illustrated manual for identification. The Pennsylvania State University Press. University park and London, 193 pp.

Nigh EA, Thomason IJ and Van Gundy SD 1980. Identification and distribution of fungal parasites of Heterodera schachtii eggs in California. Phytopathology 70: 884-889.

Nordbring-Hertz B, Jansson H-B and Tunlid A 2006. Nematophagous fungi. Encyclopedia of Life Sciences, John Wiley \& Sons, Ltd., 1-11.

Potter JW and Olthof THA 1993. Nematode pests of vegetable crops. In: Plant parasitic nematodes in temperate agriculture. K Evans, Trudgill DL and Webster JM (eds), CAB International, Wallingford, UK. pp. 171-207.

Rodrigues-Kabana R, Morgan-Jones G, Godoy G and Gintis BO 1984. Effectiveness of species of Gliocladium, Paecilomyces and Verticillium for control of Meloidogyne arenaria in field soil. Nematropica 14: 155-170.

Schlang JW, Stendel JW and Muller J 1988. Influence of resistant green mature crops on the population dynamics of Heterodera schachtii and its fungal egg parasites. Proceedings of the European Society of Nematologists $19^{\text {th }}$ International Nematology Symposium, Uppsala, Sweden. p. 69 (Abstr.).

Williams OKJ 1973. Meloidogyne incognita. C.I.H. Descriptions of Plant-Parasitic Nematodes. Set.2, No: 18. Commonwealth Institute of Parasitology. C.A.B. International. pp. 4.

$\mathrm{Yu}$, Q. 1989. Selection of promising fungi for biocontrol of nematodes. MS thesis. Catholic University of Leuven. Faculty of Agricultural Sciences. Leuven, Belgium, pp. 73. 